\title{
Rapid slip-deficit rates at the eastern margin of the Tibetan Plateau prior to the 2008 M w 7.9 Wenchuan earthquake
}

\section{Citation}

Thompson, T. Ben, Andreas Plesch, John H. Shaw, and Brendan J. Meade. 2015. “ Rapid Slip-Deficit Rates at the Eastern Margin of the Tibetan Plateau Prior to the 2008 M w 7.9 Wenchuan Earthquake." Geophysical Research Letters 42 (6) (March 17): 1677-1684. Portico. doi:10.1002/2014gl062833.

\section{Published Version}

doi:10.1002/2014GL062833

\section{Permanent link}

http://nrs.harvard.edu/urn-3:HUL.InstRepos:30168448

\section{Terms of Use}

This article was downloaded from Harvard University's DASH repository, and is made available under the terms and conditions applicable to Other Posted Material, as set forth at http:// nrs.harvard.edu/urn-3:HUL.InstRepos:dash.current.terms-of-use\#LAA

\section{Share Your Story}

The Harvard community has made this article openly available.

Please share how this access benefits you. Submit a story.

Accessibility 


\section{Geophysical Research Letters}

\author{
RESEARCH LETTER \\ 10.1002/2014GL062833 \\ Key Points: \\ - Longmen Shan GPS velocities \\ consistent with $9 \mathrm{~mm} / \mathrm{yr}$ \\ slip-deficit rates \\ - Earthquake cycle model with \\ ramp fault, detachment fault, and \\ surface topography \\ - Inference of 600 year recurrence \\ interval for Wenchuan-like \\ earthquakes
}

Correspondence to: T. Ben Thompson, tthompson@fas.harvard.edu

\section{Citation:}

Thompson, T. B., A. Plesch, J. H. Shaw, and B. J. Meade (2015), Rapid slip-deficit rates at the eastern margin of the Tibetan Plateau prior to the $2008 M_{w} 7.9$ Wenchuan earthquake, Geophys. Res. Lett., 42, 1677-1684, doi:10.1002/2014GL062833.

Received 10 DEC 2014 Accepted 12 FEB 2015 Accepted article online 16 FEB 2015 Published online 17 MAR 2015

\section{Rapid slip-deficit rates at the eastern margin of the Tibetan Plateau prior to the 2008 $M_{w} 7.9$ Wenchuan earthquake}

\author{
T. Ben Thompson ${ }^{1}$, Andreas Plesch ${ }^{1}$, John H. Shaw ${ }^{1}$, and Brendan J. Meade ${ }^{1}$ \\ ${ }^{1}$ Department of Earth and Planetary Sciences, Harvard University, Cambridge, Massachusetts, USA
}

\section{Introduction}

The Longmen Shan range is the steepest margin of the Tibetan Plateau, rising $5 \mathrm{~km}$ over a distance of only $30 \mathrm{~km}$ at the western edge of the Sichuan Basin. In 2008, the $M_{w} 7.9$ Wenchuan earthquake ruptured the Beichan and Penguan range-front thrusts $\sim 250 \mathrm{~km}$ along strike, leading to approximately 70,000 fatalities [Hubbard and Shaw, 2009; Xu et al., 2009; Lin et al., 2009]. The energy release associated with the Wenchuan earthquake requires a complimentary period of strain accumulation. However, interseismic GPS velocities measured prior to the occurrence of the Wenchuan earthquake have been interpreted as indicating negligible shortening [King et al., 1997; Chen et al., 2000; Shen et al., 2005; Meade, 2007a; Loveless and Meade, 2011]. This apparent lack of present-day shortening across the steepest topography of the India-Asia collision has been hypothesized to result from lower crustal inflation tectonic model for the eastern Tibetan Plateau [Royden et al., 1997; Bird, 1991; Burchfiel et al., 2008; Clark and Royden, 2000]. But these models do not provide a mechanism for accumulating the elastic strain released coseismically during the Wenchuan earthquake nor do they explain the significant crustal shortening and active geologic structures along the range front [Hubbard et al., 2010; Li et al., 2010; Wang et al., 2013, 2014]. Recent observations of coseismic and postseismic slip on a deep detachment to the west of the Beichuan Fault [Qi et al., 2011; Fielding et al., 2013] motivate a new model of Longmen Shan interseismic shortening that includes a locked detachment.

Previous estimates of geodetically constrained shortening and slip-deficit rates in the Longmen Shan region can be categorized into those that either (1) do not explicitly treat earthquake cycle effects [Chen et al., 2000; Shen et al., 2005; Thatcher, 2007] or (2) those that use block models, with a first-order quasi-static approximation of earthquake cycle effects but coarse representations of fault system geometry [Meade, 2007a; Burchfiel et al., 2008; Loveless and Meade, 2011]. The inferred slip-deficit rates range from $0.0 \mathrm{~mm} / \mathrm{yr}$ [Thatcher, 2007] to $3.2 \mathrm{~mm} / \mathrm{yr}$ [Loveless and Meade, 2011], with all analyses reporting significant strain 100-200 km northwest of the Longmen Shan in a region termed the Songpan-Xihe deformation zone [Shen et al., 2005]. Here we present results from a two-dimensional boundary element model that includes earthquake cycle and topographic effects to explain the regional geodetic velocities as the result of interseismic locking on both the range-front Beichuan Fault and a $20 \mathrm{~km}$ deep detachment beneath the hinterland. This fault system geometry is consistent with structural observations [Hubbard et al., 2010; $L i$ et al., 2010] and the inference of 2-6 m of slip of a $20 \mathrm{~km}$ deep detachment that extends $90 \mathrm{~km}$ northwest using interferometric synthetic aperture radar measurements and post-Wenchuan GPS observations [Qi et al., 2011; Fielding et al., 2013]. Integrating range front and detachment fault system geometry, 


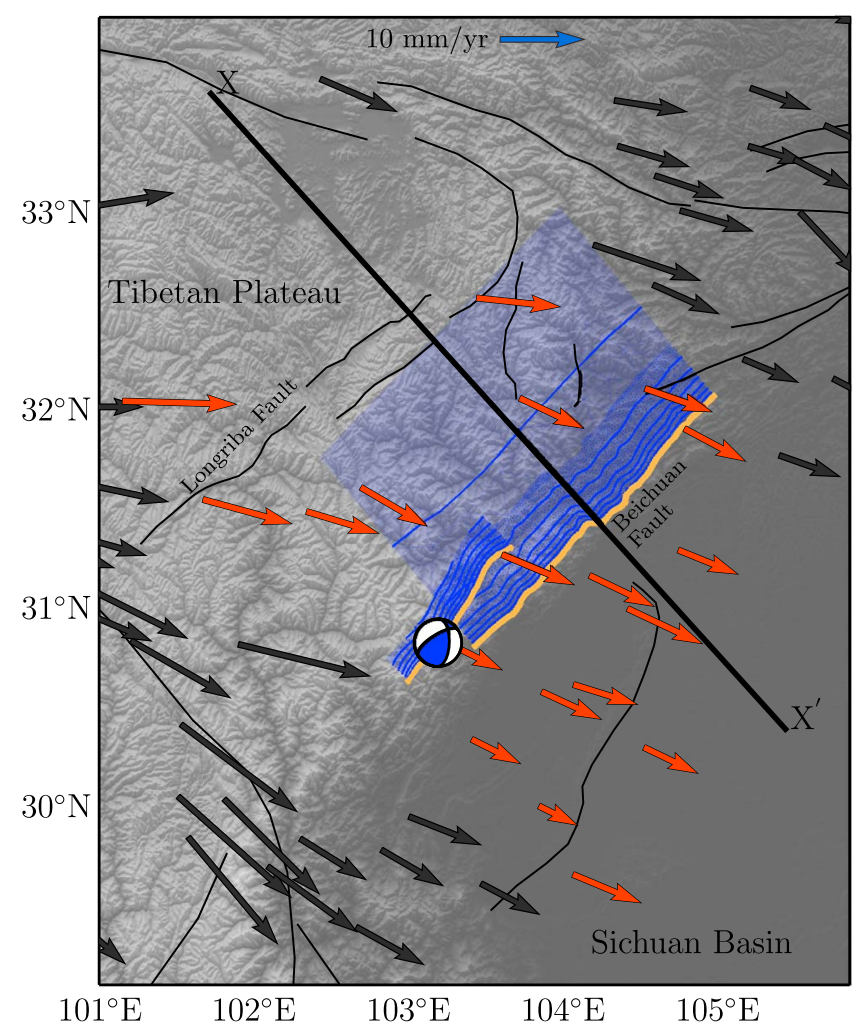

Figure 1. Tectonic setting of the $M_{w} 7.9$ Wenchuan earthquake and Longmen Shan range front. The focal mechanism is located at the epicenter of the Wenchuan earthquake and the thick yellow line shows the surface trace of rupture. The thin blue lines show $3 \mathrm{~km}$ depth contours of the fault model. GPS velocity vectors ([Gan et al., 2007] are colored red if they are included in the two-dimensional models we consider. The black line $X-X^{\prime}$ shows the two-dimensional cross section we study. Thin black lines indicate other significant faults in the region [Taylor and Yin, 2009]. we develop a model of interseismic strain accumulation that is consistent with both interseismic GPS velocities measured prior to the Wenchuan earthquake and previous observations of coseismic and postseismic strains release at depth. Importantly, the model provides a mechanism for large slip-deficit rates in the absence of a localized velocity gradient at the Longmen Shan range front.

\section{Geodetic Analysis of Longmen Shan Shortening and Slip-Deficit Rates}

The geometry of the Beichuan Fault and the detachment to the west has been inferred from structural interpretations [Hubbard et al., 2010] and seismic reflection observations [Zhang et al., 2009; Guo et al., 2013]. The Beichuan Fault is part of an imbricate thrust system, with fault dips steepening to the northwest. Structural imbrication is typically produced by stacked listric faults that sole to detachments.

Furthermore, the large synclinorium parallel to, and west of, the Beichuan Fault is consistent with the Beichuan Fault shallowing to a detachment based on fault-bend folding theory [Suppe, 1983; Hubbard et al., 2010]. In our model, the range-front Beichuan

Fault dips steeply at $\sim 53^{\circ}$ at its surface trace shallowing to subhorizontal $\sim 20 \mathrm{~km}$ depth where it merges with the detachment surface. At $15 \mathrm{~km}$ depth, a $35^{\circ}$ dip is consistent with focal mechanism inversions [Hubbard et al., 2010]. Extrapolating from the regional dip of the Sichuan Basin as it extends beneath the Longmenshan range front [Hubbard et al., 2010; Guo et al., 2013], the detachment in our model dips $\sim 1.5^{\circ}$ from an initial depth of $20 \mathrm{~km}$ to a depth of $23 \mathrm{~km}$ at a distance of $110 \mathrm{~km}$ to the northwest. The depth, dip, and extent of the detachment are similar to the best fitting surface found by Qi et al. [2011] in fitting the coseismic and postseismic slip of the Wenchuan earthquake. For our interseismic shortening and slip-deficit models we use an idealized two-dimensional representation of these fault surfaces (Figure 1).

The inference that a $20 \mathrm{~km}$ deep detachment slipped, either coseismically or postseismically, at distances up to $100 \mathrm{~km}$ from the range front [Qi et al., 2011], necessitates including interseismic GPS velocities at a similar distance into the interior of the Tibetan Plateau (Figure 1). We analyze interseismic GPS velocities measured during the decade prior to the Wenchuan earthquake [Gan et al., 2007], in a nominally Eurasian reference frame [Apel et al., 2006]. We exclude velocities that are near other major active structures including the Xianshuihe and Kunlun Faults (Figure 1).

To model both the tectonic and earthquake cycle processes contributing to these interseismic GPS data, we use a quasi-static elastic boundary element software under active development. An important feature of our tool is the inclusion of accurate surface topography in steep mountainous regions or Earth curvature in large-scale problems. Previous boundary element methods in the Earth sciences [Thomas, 1993; Cooke and Dair, 2011; Maerten et al., 2014] have been based on analytic integrations of rectangular or triangular slip surfaces [Okada, 1992; Meade, 2007b]. These analytic formulae normally assume an infinite half-space 
geometry and piecewise constant slip. Even so, they are time consuming to derive. To avoid these limitations, the basis for our boundary element formulation is numerical quadrature of the integrals in the full-space elastic Somigliana identity [Cruse, 1969]. The difficulty in this approach is that straightforward quadrature methods (for example, Gaussian quadrature) assume a smooth integrand. For observation points on or very close to a surface, including the free surface, the integrand is singular. We resolve this problem by evaluating singular integrals as the limit of a sequence of nonsingular integrals. This approach is similar to analytical limit to the boundary methods [Sutradhar et al., 2008] and series-expansion methods [Klöckner et al., 2013]. Our tests of relative error show that this quadrature-based method can match, to arbitrary precision, analytically derived half-space solutions and is free of the singularities present in those solutions. This entirely numerical boundary element method allows for complete flexibility in representing both variable surface topography and complex fault system geometries. The steep topography of the Longmen Shan range front is included via the SRTM30_PLUS digital elevation data set [Becker et al., 2009].

Using this boundary element model, we solve for the single best fitting shortening rate between the Tibetan Plateau and the Sichuan Basin while maintaining kinematic consistency using a two-dimensional block formulation and imposing zero traction boundary conditions on the free surface. In a purely elastic model, a locked fault is eventually required to slip to account for relative block motions. The rate of accumulation of this eventual slip, the slip-deficit rate, $s_{\text {sd }}$, is related to the local fault dip, $\delta$, and total shortening rate, $v_{0}$, by $s_{\text {sd }}=v_{0} / \cos \delta$ [McCaffrey, 2002; Meade and Hager, 2005]. As a result, slip-deficit rates are strictly larger than shortening rates to maintain smoothly varying horizontal surface velocities. The influence of the interseismic slip deficit on the fault geometry is subtracted from block motion to calculate the interseismic velocity profile [Savage, 1983; Meade and Hager, 2005].

The velocity gradient across the Longmen Shan range front is negligible (Figure 2a). To fit these observed near-field data, any planar or listric geometry with interseismic locking limited to the range front (for example, a Beichuan-only fault geometry) would require near-zero slip-deficit rates. Such a model is inconsistent with slip during the Wenchuan earthquake on the Beichuan and Penguan Faults and with geologic estimates of significant shortening [Hubbard et al., 2010; Li et al., 2010; Wang et al., 2013, 2014]. It is also inconsistent with coseismic and postseismic slip on the detachment [Qi et al., 2011; Fielding et al., 2013].

The inclusion of a locked detachment, however, shifts the predicted location of the steep interseismic velocity gradient far to the northwest (Figure 2a). When including a locked detachment, the least squares best fit shortening rate for the Longmen Shan region is $5.7 \pm 1.5 \mathrm{~mm} / \mathrm{yr}$. The spatial distribution of interseismic deformation is affected by the fault geometry and kinematic consistency constraints is represented in terms of the slip-deficit rate which ranges from $5.7 \mathrm{~mm} / \mathrm{yr}$ on the deep detachment to $9.5 \mathrm{~mm} / \mathrm{yr}$ at the surface trace of the Beichuan Fault (Figure $2 \mathrm{~b}$ ). Figure $2 \mathrm{c}$ shows the horizontal velocities as a function of depth, demonstrating that the velocity gradients derive from a locked to creeping transition at the detachment tip. The smoothing behavior of an elastic Earth prevents distinguishing between a sharp drop in slip-deficit and a gradual change over many kilometers. These results demonstrate a mechanism for interseismic strain accumulation to be most clearly evident far from the range front structures where large coseismic slip occurs.

The primary uncertainty in our shortening estimate is the lack of good constraints on the detachment geometry in the hinterland. However, assuming the geometry is correct, two further forms of error are evident. First, the uncertainty in true interseismic velocities is propagated through to the estimated shortening, resulting in the gray region of uncertainty in Figure 2a. Further, the sparsity of observations suggests that certain observations may have undue influence on the shortening estimate. Excluding the northwestmost observation decreases the best fit shortening to $3.9 \pm 1.9 \mathrm{~mm} / \mathrm{yr}$, with a near-surface slip-deficit rate of $6.5 \pm 3.2 \mathrm{~mm} / \mathrm{yr}$ on the Beichuan Fault. The least squares uncertainty is increased (from $1.5 \mathrm{~mm} / \mathrm{yr}$ to $1.9 \mathrm{~mm} / \mathrm{yr}$ ) because the northwestern portion of velocities is poorly constrained once the observation is excluded. This northwesternmost observation is adjacent to the Longriba Fault and thus may be impacted by interseismic strain accumulation on this structure. However, the Longriba Fault is primarily a dextral strike-slip fault [Ren et al., 2013], so its influence should be predominantly orthogonal to the profile-parallel velocities we examine here.

To further quantify the sensitivity of slip-deficit rate estimates to variability in data selection we perform a complete case resampling bootstrap. Shortening and slip-deficit rates are calculated for all possible subsets of the observed GPS velocities. There are $2^{20}=1,048,576$ possible subsets of the observations (Figure 3 ). 

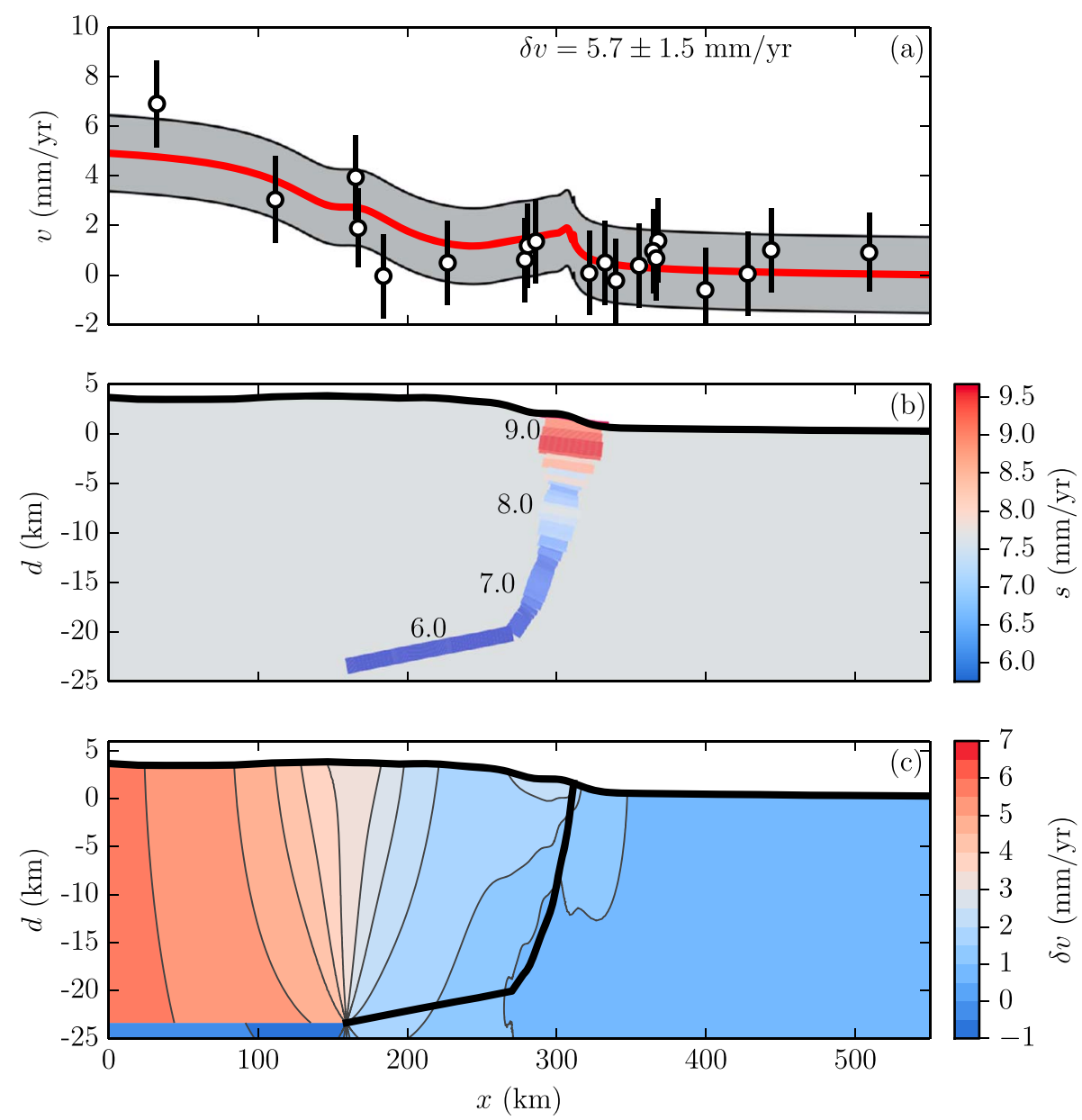

Figure 2. GPS velocities, model geometry, and inferend slip-deficit rates. (a) Observed profile-parallel horizontal observed velocities are shown in black with $68 \%$ confidence error bars. Model-predicted velocities are shown by the red line with the surrounding gray region showing a $68 \%$ confidence interval. (b) Model geometry with colors and width along the locked fault showing predicted slip-deficit rates. Because shortening is the horizontal component of slip deficit, increasing dips near the surface lead to larger slip deficits. (c) Predicted horizontal velocity as a function of depth. Note the steep velocity gradient and corresponding strain accumulation above the end of the detachment surface. Vertical axes are exaggerated in all panels.

We sample jointly from this slip-deficit distribution and the distribution of surface area weighted fault depths. This analysis demonstrates that the majority of the slip-deficit depth probability landscape lies at slip-deficit rates between 4 and $6 \mathrm{~mm} / \mathrm{yr}$. In the steepest, near-surface portion of the range front has minimum slip-deficit rates of $\sim 6 \mathrm{~mm} / \mathrm{yr}$, with an $\sim 25 \%$ chance of slip-deficit rates above $10 \mathrm{~mm} / \mathrm{yr}$ (Figure 3). This geodetically constrained slip-deficit rate can provide a mechanism for the rapid loading of the faults that exhibited 5-7 m of near-surface coseismic slip during the Wenchuan earthquake [Xu et al., 2009; Shen et al.,2009].

We also quantify the effect of explicitly treating surface topography. By comparing models with and without surface topography, the local minimum in velocity (Figure 2a) northwest of the Beichuan is the main topographic feature. The very steep, but short-wavelength, spike in velocity immediately northwest of the fault trace is the other topographic feature. Without topography, these portions of the velocity field show a smoother transition from the Tibetan block motion to the Sichuan block motion. The maximum difference in estimated velocity fields between a model with a flat surface and a model with the true topography is $\sim 15 \%$. Consequently, geodetic analyses in steep regions should consider topographic effects to avoid systematic bias. Topographic effects should be more pronounced with a shallower fault dip or for coseismic displacements where deformation is localized in regions of steep topography. 


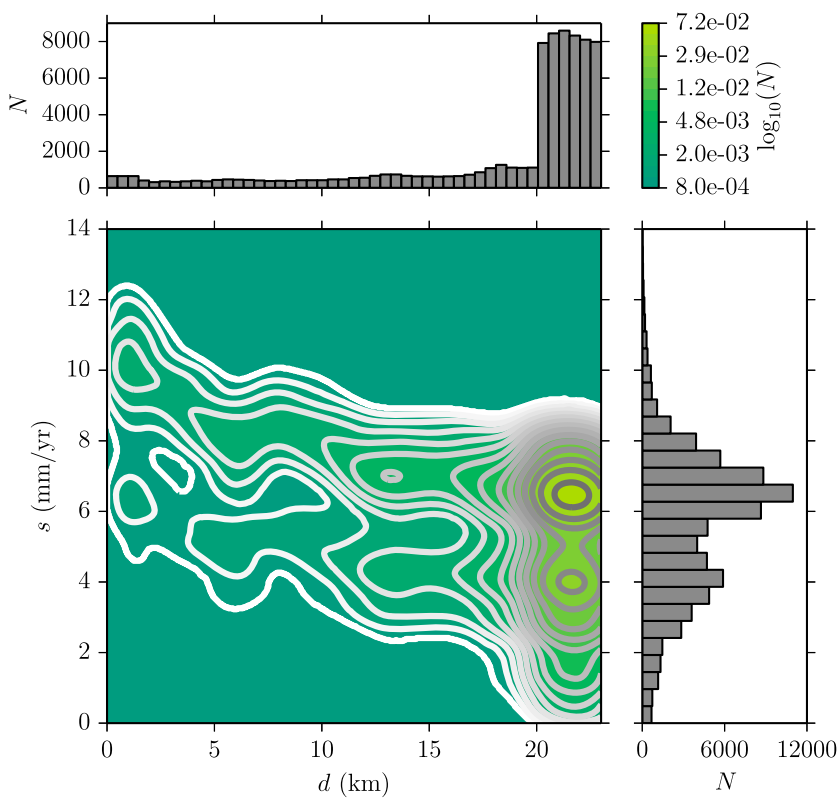

Figure 3. The depth-slip-deficit probability landscape. The upper histogram is the projection of the contour plot onto a depth histogram, demonstrating that the majority of the fault surface area lies on the deep detachment. The right histogram is the projection of the contour plot onto a slip-deficit rate histogram showing that the majority of fault surface area is accumulating slip-deficit at rates near $6 \mathrm{~mm} / \mathrm{yr}$.

\section{Implications for the Longmen Shan Earthquake Cycle}

The fundamental effect of allowing a $20 \mathrm{~km}$ deep detachment to accumulate and release elastic strain through the earthquake cycle is the lack of a range-front geodetic signature despite the significant (5-10 mm/yr) slip-deficit rate (Figure $2 \mathrm{a}$ ). Locking on the deep detachment obscures the signal of deformation on range-front faults. The interseismic deformation is broadly distributed across $300 \mathrm{~km}$. Interseismically, the easternmost Tibetan Plateau moves cohesively with the Sichuan Basin, with an apparent block boundary 100-200 km northwest of the range front. This apparent block boundary has been identified previously as the Songpan-Xihe deformation zone [Shen et al., 2005]. Despite this apparent block boundary, coseismic slip is concentrated at the range front.

Prior analyses of interseismic deformation at the Longmen Shan including the effects of dipping fault system geometry and earthquake cycle effects have been limited [Loveless and Meade, 2011; Qi et al., 2011; Hao et al., 2014]. Of these only the three-dimensional block model of Loveless and Meade [2011] is kinematically consistent [Minster and Jordan, 1987; McCaffrey, 2002; Meade and Hager, 2005]. Compared to their estimated slip-deficit rate of $3.2 \mathrm{~mm} / \mathrm{yr}$, our estimate is 2.5 times as large. Their calculations indicate a maximum 37\% likelihood of internal block strain west of the Longmen Shan region [Loveless and Meade, 2011]. Attributing that block-internal strain to a deep detachment instead can explain the discrepancy between the two models. Our model of far-field deformation is also consistent with a similar detachment model of leveling and GPS-based uplift rates [Hao et al., 2014]. The vertical velocities they measure increase from the Longmen Shan range front until peaking $50 \mathrm{~km}$ southeast of the Longriba fault zone at approximately $3.5 \mathrm{~mm} / \mathrm{yr}$ of uplift. The Longriba fault zone has the wrong slip-sense (thrusting up to the southeast [Ren et al., 2013]) to accommodate such vertical deformation. No other identified structures are nearby.

The velocity gradient that we link to the physics of the earthquake cycle and mapped fault system geometry has been alternatively asserted to represent distributed strain across the eastern Tibetan Plateau [Royden et al., 2008]. Relatedly, Kirby et al. [2007] study an eastward decrease in interseismic velocities across the Kunlun Fault. They conclude that the decline in slip-rate must be attributed to internal deformation. Further, fast erosion and inferred uplift rates have been used to support lower crustal inflation models in the absence of shortening [Kirby, 2003]. All of these features can be explained with slip accommodated by a wide eastern Tibetan fold-and-thrust system, a suggestion supported by the continuation of shortening north from the Longmen Shan onto the Huya [Kirby et al., 2000] and Min Jiang Faults [Chen and Wilson, 1994].

While we have explained the observed broad GPS interseismic velocity gradient as a result of a locked fault geometry including a deep detachment, we have not addressed when the accumulated slip deficit on the deep detachment is released. Geodetically constrained estimates of coseismic and postseismic slip show up to $5 \mathrm{~m}$ of slip on a deep detachment [Qi et al., 2011]. Our data analysis depends on the detachment being locked during the period of data collection from 1998 to 2004 [Gan et al., 2007]. In addition to coseismic and short-term postseismic activity on the detachment, it is possible that intermittent aseismic slip could be an important mode of strain release. This is difficult to observationally constrain given that interseismic GPS observations cover $\sim 1 \%$ of a complete Longmen Shan earthquake cycle. Seismicity is approximately 


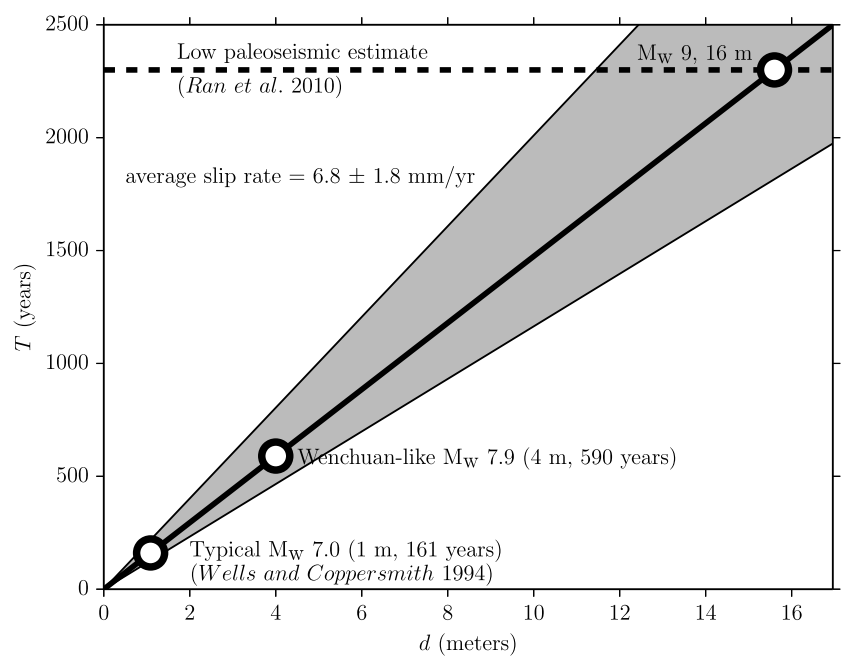

Figure 4. Earthquake recurrence intervals as a function of coseismic slip, assuming the best fit slip-deficit rate for the Beichuan Fault. The gray region indicates the uncertainty implied by the error in our shortening estimate. The discrepancy between the Wenchuan-like recurrence and the paleoseismic estimate may be due to the presence of multiple active faults in the range front. limited to the upper $20 \mathrm{~km}$ of crust in the range front [Li et al., 2010]. Using steady state critical taper wedge theory [Dahlen, 1990], with an internal coefficient of friction of 0.7 , a cohesion of $5 \mathrm{MPa}$, and a hydrostatic fluid pressure, we find a basal friction coefficient of 0.08 . This is comparable to estimates of friction on the lowangle detachment system beneath the Longmen Shan foreland [Hubbard et al., 2010], indicating a very weak fault over long time periods. On the other hand, the surface area and shortening rate of the detachment could sustain very large earthquakes if slip is released coseismically. Specifically, if $100 \mathrm{~km}$ downdip and $300 \mathrm{~km}$ along-strike were to slip $4 \mathrm{~m}$, similar to average slip during the Wenchuan earthquake, a $M_{w} 8.4$ rupture would be produced.

The $5-10 \mathrm{~mm} / \mathrm{yr}$ slip-deficit rates estimated here can be used to provide a new kinematic constraint on earthquake recurrence intervals at the Longmen Shan (Figure 4). Our shortening estimate suggests a recurrence interval for Wenchuan-like ruptures between 470 and 800 years (best fit: 590 years), with much shorter recurrence intervals for smaller events. This contrasts with the average recurrence of 2000 years inferred from paleoseismic field investigations for the Beichuan Fault [Ran et al., 2010]. The 5-10 mm/yr slip-deficit rate estimated here would imply $M_{w} 9.0$ ruptures for that recurrence interval, which would seemingly require an along-strike rupture equal to or greater than the $\sim 300 \mathrm{~km}$ along-strike length of the Longmen Shan. However, our slip-deficit estimate could include the effects of other imbricated structures, such as the Range Front Blind Thrust [Hubbard et al., 2010; Wang et al., 2014]. As a result our estimate is a system-wide estimate, while paleoseismic estimates have focused on the analysis of individual thrust faults. Furthermore, missed events in the paleoseismic record could reconcile the difference in estimated recurrence interval.

True earthquake recurrence intervals may be shorter than this geodetic estimate. First, coseismic, interseismic, and geologic slip estimates include a significant component of strike-slip motion [Shen et al., 2009; Qi et al., 2011; Densmore et al., 2007; Meade, 2007b; Loveless and Meade, 2011], while we consider an idealized case of fault normal motion only. Second, our two-dimensional model assumes plane strain conditions which will result in underestimates of the shortening required to produce far-field velocities. This is because the plane strain simplification is equivalent to assuming the fault geometry extends infinitely far along strike. Third, the modeled thrust is the steeply dipping Beichuan Fault. The foreland Range Front Blind Thrust or the shallow detachment beneath Chengdu dip more shallowly [Hubbard et al., 2010], producing a greater total range-front moment deficit. Finally, the slip-deficit rate estimates may be low due to being estimated late in the earthquake cycle (i.e., in the decade prior to the Wenchuan earthquake) when viscoelastic effects may further contribute to a low near-fault-trace velocity gradient [Savage, 2000].

\section{Conclusion}

Previous inferences of near-zero interseismic shortening estimates at the Longmen Shan have been difficult to reconcile with the large moment release during the Wenchuan earthquake, very steep topography and structural interpretations indicating fold-and-thrust geometry. We offer a possible resolution to this conflict by including earthquake cycle effects associated with interseismic locking on the Beichuan Fault and a $20 \mathrm{~km}$ deep detachment to the west. Our revised interseismic shortening rate is $5.7 \pm 1.5 \mathrm{~mm} / \mathrm{yr}$ with on-fault slip-deficit rates up to $9.5 \mathrm{~mm} / \mathrm{yr}$ near the surface where the Beichuan Fault is most steeply dipping. The model demonstrates that interseismic strain accumulation may be spatially disjoint from coseismic 


\section{Acknowledgments}

The data and code used for this paper can be obtained from the corresponding author via email. T. Ben Thompson acknowledges the support of the Department of Energy Computational Science Graduate Fellowship program under grant DE-FG02-97ER25308. The authors thank James Dolan and an anonymous reviewer for providing helpful comments and improving the clarity of the paper. Judith Hubbard provided perspectives on the development of the fault system geometry model. Computational resources were provided and maintained by Harvard FAS Research Computing.

The Editor thanks James Dolan and an anonymous reviewer for their assistance in evaluating this paper. strain release, emphasizing that accurate three-dimensional fault system geometries are critical in the analysis of geodetic data. The boundary element model presented here unifies geodetic models of coseismic, postseismic, and interseismic crustal deformation across the greater Longmen Shan region and suggests that with current loading rates, Wenchuan-like earthquakes may occur as frequently as every 600 years.

\section{References}

Apel, E. V., R. Burgmann, G. Steblov, N. Vasilenko, R. King, and A. Prytkov (2006), Independent active microplate tectonics of northeast Asia from GPS velocities and block modeling, Geophys. Res. Lett., 33, L11303, doi:10.1029/2006GL026077.

Becker, J. J., et al. (2009), Global bathymetry and elevation data at 30 Arc seconds resolution: SRTM30_PLUS, Mar. Geod., 32(4), 355-371, doi:10.1080/01490410903297766.

Bird, P. (1991), Lateral extrusion of lower crust from under high topography, in the Isostatic Limit, J. Geophys. Res., 96(B6), 10,275-10,286.

Burchfiel, B., L. Royden, R. van der Hilst, B. Hager, Z. Chen, R. King, C. Li, J. Lü, H. Yao, and E. Kirby (2008), A geological and geophysical context for the Wenchuan earthquake of 12 May 2008, Sichuan, People's Republic of China, Geol. Soc. Am. Today, 18(7), 4-11, doi:10.1130/GSATG18A.1.

Chen, S., and C. Wilson (1994), Active faulting and block movement associated with large earthquakes in the Min Shan and Longmen Mountains, northeastern Tibetan Plateau, J. Geophys. Res., 99(B12), 24,025-24,038.

Chen, Z., B. C. Burchfiel, Y. Liu, R. W. King, L. H. Royden, W. Tang, E. Wang, J. Zhao, and X. Zhang (2000), Global positioning system measurements from eastern Tibet and their implications for India/Eurasia intercontinental deformation, J. Geophys. Res., 105(B7), $16,215-16,227$

Clark, M., and L. Royden (2000), Topographic ooze: Building the eastern margin of Tibet by lower crustal flow, Geology, 28(8), $703-706$. Cooke, M. L., and L. C. Dair (2011), Simulating the recent evolution of the southern big bend of the San Andreas Fault, Southern California, J. Geophys. Res., 116, B04405, doi:10.1029/2010JB007835.

Cruse, T. (1969), Numerical solutions in three dimensional elastostatics, Int. J. Solids Struct., 5, 1259-1274.

Dahlen, F. A. (1990), Critical taper model of fold-and-thrust belts and accretionary wedges, Annu. Rev. Earth Planet. Sci., $18,55-99$.

Densmore, A. L., M. A. Ellis, Y. Li, R. Zhou, G. S. Hancock, and N. Richardson (2007), Active tectonics of the Beichuan and Pengguan faults at the eastern margin of the Tibetan Plateau, Tectonics, 26, TC4005, doi:10.1029/2006TC001987.

Fielding, E. J., A. Sladen, Z. Li, J.-P. Avouac, R. Burgmann, and I. Ryder (2013), Kinematic fault slip evolution source models of the 2008 M7.9 Wenchuan earthquake in China from SAR interferometry, GPS and teleseismic analysis and implications for Longmen Shan tectonics, Geophys. J. Int., 194(2), 1138-1166, doi:10.1093/gji/ggt155.

Gan, W., P. Zhang, Z.-K. Shen, Z. Niu, M. Wang, Y. Wan, D. Zhou, and J. Cheng (2007), Present-day crustal motion within the Tibetan Plateau inferred from GPS measurements, J. Geophys. Res., 112, B08416, doi:10.1029/2005JB004120.

Guo, X., R. Gao, G. Randy Keller, X. Xu, H. Wang, and W. Li (2013), Imaging the crustal structure beneath the eastern Tibetan Plateau and implications for the uplift of the Longmen Shan range, Earth Planet. Sci. Lett., 379, 72-80, doi:10.1016/j.epsl.2013.08.005.

Hao, M., Q. Wang, Z. Shen, D. Cui, L. Ji, Y. Li, and S. Qin (2014), Present day crustal vertical movement inferred from precise leveling data in eastern margin of Tibetan Plateau, Tectonophysics, 632, 281-292, doi:10.1016/j.tecto.2014.06.016.

Hubbard, J., and J. H. Shaw (2009), Uplift of the Longmen Shan and Tibetan Plateau, and the 2008 Wenchuan (M = 7.9) earthquake Nature, 458(7235), 194-7, doi:10.1038/nature07837.

Hubbard, J., J. H. Shaw, and Y. Klinger (2010), Structural Setting of the 2008 Mw 7.9 Wenchuan, China, Earthquake, Bull. Seismol. Soc. Am., 100, 2713-2735, doi:10.1785/0120090341.

King, R. W., F. Shen, B. C. Burchfiel, L. H. Royden, E. C. Wang, Z. L. Chen, Y. P. Liu, X. Y. Zhang, J. X. Zhao, and Y. L. Li (1997), Geodetic measurement of crustal motion in southwest China, Geology, 25(2), 179-182.

Kirby, E. (2003), Distribution of active rock uplift along the eastern margin of the Tibetan Plateau: Inferences from bedrock channel longitudinal profiles, J. Geophys. Res., 108(B4), 2217, doi:10.1029/2001JB000861.

Kirby, E., K. X. Whipple, B. C. Burchfiel, W. Tang, G. Berger, Z. Sun, and Z. Chen (2000), Neotectonics of the Min Shan, China: Implications for mechanisms driving Quaternary deformation along the eastern margin of the Tibetan Plateau, Geol. Soc. Am. Bull., 112(3), 375-393, doi:10.1130/0016-7606(2000)112<375:NOTMSC >2.0.CO;2.

Kirby, E., N. Harkins, E. Wang, X. Shi, C. Fan, and D. Burbank (2007), Slip rate gradients along the eastern Kunlun Fault, Tectonics, 26, TC2010, doi:10.1029/2006TC002033.

Klöckner, A., A. Barnett, L. Greengard, and M. O'Neil (2013), Quadrature by expansion: A new method for the evaluation of layer potentials, J. Comput. Phys., 252, 332-349, doi:10.1016/j.jcp.2013.06.027.

Li, Y., D. Jia, J. H. Shaw, J. Hubbard, A. Lin, M. Wang, L. Luo, H. Li, and L. Wu (2010), J. Geophys. Res., 115, B04317, doi:10.1029/2009JB006824

Lin, A., Z. Ren, D. Jia, and X. Wu (2009), Co-seismic thrusting rupture and slip distribution produced by the $2008 \mathrm{Mw} 7.9 \mathrm{Wenchuan}$ earthquake, China, Tectonophysics, 471(3-4), 203-215, doi:10.1016/j.tecto.2009.02.014.

Loveless, J., and B. Meade (2011), Partitioning of localized and diffuse deformation in the Tibetan Plateau from joint inversions of geologic and geodetic observations, Earth Planet. Sci. Lett., 303(1-2), 11-24, doi:10.1016/j.epsl.2010.12.014.

Maerten, F., L. Maerten, and D. Pollard (2014), iBem3D, a three-dimensional iterative boundary element method using angular dislocations for modeling geologic structures, Comput. Geosci., 72, 1-17, doi:10.1016/j.cageo.2014.06.007.

McCaffrey, R. (2002), Crustal block rotations and plate coupling, in Plate Boundary Zones, Geodynamics Series, vol. 30, edited by S. Stein and J. T. Freymueller, pp. 101-122, AGU, Washington, D. C., doi:10.1029/030GD06.

Meade, B. J. (2007a), Present-day kinematics at the India-Asia collision zone, Geology, 35(1), 81-84, doi:10.1130/G22924A.1.

Meade, B. J. (2007b), Algorithms for the calculation of exact displacements, strains, and stresses for triangular dislocation elements in a uniform elastic half space, Comput. Geosci., 33(8), 1064-1075, doi:10.1016/j.cageo.2006.12.003.

Meade, B. J., and B. H. Hager (2005), Block models of crustal motion in southern California constrained by GPS measurements, J. Geophys. Res., 110, B03403, doi:10.1029/2004JB003209.

Minster, J. B., and T. H. Jordan (1987), Vector constraints on western United-States deformation from space geodesy, neotectonics, and plate motions, J. Geophys. Res., 92(B6), 4798-4804.

Okada, Y. (1992), Internal deformation due to shear and tensile faults in a half-space, Bull. Seismol. Soc. Am., 82(2), 1018-1040.

Qi, W., Q. Xuejun, L. Qigui, J. Freymueller, Y. Shaomin, X. Caijun, Y. Yonglin, Y. Xinzhao, T. Kai, and C. Gang (2011), Rupture of deep faults in the 2008 Wenchuan earthquake and uplift of the Longmen Shan, Nat. Geosci., 4(9), 634-640, doi:10.1038/NGEO1210. 
Ran, Y., L. Chen, J. Chen, H. Wang, G. Chen, J. Yin, X. Shi, C. Li, and X. Xu (2010), Paleoseismic evidence and repeat time of large earthquakes at three sites along the Longmenshan fault zone, Tectonophysics, 491(1-4), 141-153, doi:10.1016/j.tecto.2010.01.009.

Ren, J., X. Xu, R. S. Yeats, and S. Zhang (2013), Latest Quaternary paleoseismology and slip rates of the Longriba fault zone, eastern Tibet: Implications for fault behavior and strain partitioning, Tectonics, 32(2), 216-238, doi:10.1002/tect.20029.

Royden, L. H., B. C. Burchfiel, R. W. King, E. Wang, Z. L. Chen, F. Shen, and Y. P. Liu (1997), Surface deformation and lower crustal flow in eastern Tibet, Science, 276(5313), 788-790.

Royden, L. H., B. Burchfiel, and R. van der Hilst (2008), The geological evolution of the Tibetan Plateau, Science, 1054, doi:10.1126/science.1155371.

Savage, J. (2000), Viscoelastic-coupling model for the earthquake cycle driven from below, J. Geophys. Res., 105(B11), 25,525-25,532.

Savage, J. C. (1983), A dislocation model of strain accumulation and release at a subduction zone, J. Geophys. Res., 88(B6), 4984-4996.

Shen, Z. K., J. N. Lu, M. Wang, and R. Bürgmann (2005), Contemporary crustal deformation around the southeast borderland of the Tibetan Plateau, J. Geophys. Res., 110, B11409, doi:10.1029/2004JB003421.

Shen, Z.-K., J. Sun, P. Zhang, Y. Wan, M. Wang, R. Bürgmann, Y. Zeng, W. Gan, H. Liao, and Q. Wang (2009), Slip maxima at fault junctions and rupturing of barriers during the 2008 Wenchuan earthquake, Nat. Geosci., 2(10), 718-724, doi:10.1038/ngeo636.

Suppe, J. (1983), Geometry and kinematics of fault-bend folding, Am. J. Sci., 283, 684-721.

Sutradhar, A., G. H. Paulino, and L. J. Gray (2008), Symmetric Galerkin Boundary Element Method, Springer, Berlin.

Taylor, M., and A. Yin (2009), Active structures of the Himalayan-Tibetan orogen and their relationships to earthquake distribution, contemporary strain field, and Cenozoic volcanism, Geosphere, 5(3), 199-214, doi:10.1130/GES00217.1.

Thatcher, W. (2007), Microplate model for the present-day deformation of Tibet, J. Geophys. Res., 112, B01401, doi:10.1029/2005JB004244.

Thomas, A. L. (1993), Poly3D: A three-dimensional, polygonal element, displacement discontinuity boundary element computer program with applications to fractures, faults, and cavities in the Earth's Crust, PhD thesis, Stanford Univ., Stanford, Calif.

Wang, M., D. Jia, J. H. Shaw, J. Hubbard, A. Lin, Y. Li, and L. Shen (2013), Active fault-related folding beneath an alluvial terrace in the Southern Longmen Shan Range Front, Sichuan Basin, China: Implications for seismic hazard, Bull. Seismol. Soc. Am., 103(4), 2369-2385, doi:10.1785/0120120188.

Wang, M., D. Jia, J. H. Shaw, J. Hubbard, A. Plesch, Y. Li, and B. Liu (2014), The 2013 Lushan earthquake: Implications for seismic hazards posed by the Range Front blind thrust in the Sichuan Basin, China, Geology, 42(10), 915-918, doi:10.1130/G35809.1.

Xu, X., X. Wen, G. Yu, G. Chen, Y. Klinger, J. Hubbard, and J. Shaw (2009), Coseismic reverse- and oblique-slip surface faulting generated by the $2008 \mathrm{Mw} 7.9$ Wenchuan earthquake, China, Geology, 37(6), 515-518, doi:10.1130/G25462A.1.

Zhang, Z., Y. Wang, Y. Chen, G. A. Houseman, X. Tian, E. Wang, and J. Teng (2009), Crustal structure across Longmenshan Fault belt from passive source seismic profiling, Geophys. Res. Lett., 36, L17310, doi:10.1029/2009GL039580. 